\title{
Identification of material constitutive law constants using machining tests: a response surface methodology based approach
}

\author{
M. Daoud, W. Jomaa, J. F. Chatelain, A. Bouzid \& V. Songmene \\ Department of Mechanical Engineering, \\ École de technologie supérieur (ÉTS), Canada
}

\begin{abstract}
The finite element modeling (FEM) of chip formation is one of the most reliable tools for the prediction and optimization of machining processes; thanks to the high performance of advanced computers and robust finite element codes which made the modeling of complex machining processes (turning, milling, and drilling) possible. The success of any FEM strongly depends on constitutive law which characterizes the thermo-mechanical behavior of the machined materials. Johnson and Cook's (JC) constitutive model is widely used in the modeling of machining processes. However, one can find in the literature, different coefficients of JC's constitutive law for the same material which can significantly affect the predicted results (cutting forces, temperatures, etc.). These differences were attributed to the different methods used for the determination of the material parameters. In the present work, an inverse method, based on orthogonal machining tests, was developed to determine the parameters of the JC constitutive law. The originality of this study lies in the use of the response surface methodology (RSM) as a technique to improve the existing inverse method. The studied material is a $6061 \mathrm{~T} 6$ high strength aluminum alloy. It is concluded that the calculated flow stresses obtained from the proposed approach were in a good agreement with the experimental ones. Moreover, the material parameters obtained from the present study predict more accurate values of flow stresses as compared to those reported in the literature.

Keywords: Johnson-Cook constitutive law, identification, inverse method, response surface methodology, machining, AA6061-T6.
\end{abstract}




\section{Introduction}

Finite element modeling (FEM) is the most attractive computational tool used to simulate metal cutting processes (i.e. turning, milling and drilling). It avoids experimentation costs and lengthy manufacturing times. The use of an accurate flow stress model is highly important in any metal cutting simulation. The constitutive model proposed by Johnson and Cook (JC) (Johnson and Cook [1]), is widely used in the modeling of machining processes. Unfortunately, the different coefficients provided in the literature for the same material are not reliable since they significantly affect the predicted results (cutting forces, temperatures, etc.). These discrepancies could be attributed to the different methods used for the determination of the material parameters. The existing methods include static tests (tensile, compression), dynamic tests (SplitHopkinson bar technique, SHBT), inverse method (machining test) and a combination between them. The Split-Hopkinson bar technique (SHBT) is often used to study material behavior at high strain rate $\left(10^{3}\right.$ to $10^{4} \mathrm{~S}^{-1}$ ) (Lesuer et al. [2]). It experiences some technical difficulties that could affect the accuracy of the final results according to Guo [3]. Rule [4] has used the Taylor test with strain rates up to $10^{5} S^{-1}$ for the identification of the JC constitutive parameters. However, the strains encountered in this test are indeed less than 1 which are often less than those induced by machining. Moreover, these techniques are costly, complex, and difficult to run (Panov [5]). Even though higher strain rates and strains are achieved by dynamic tests, they are still far from representing the real thermo-mechanical loading encountered in machining. In order to achieve accurate metal cutting simulation, material constants must be obtained at high strain rates (up to $10^{6} \mathrm{~S}^{-1}$ ), temperatures (up to $1000^{\circ} \mathrm{C}$ ) and strains (up to 4) (Sartkulvanich et al. [6]). Recently, many approaches, based on machining tests, have been developed to identify the material constants. Shatla et al. [7] proposed a "hybrid method" to determine the material constants of the constitutive equation. The basic idea about this method is to minimize the error between the measured cutting forces and those predicted analytically using the computer code OXCUT based on Oxley's machining theory (Oxley [8]). Another approach based on FEM in conjunction with orthogonal cutting tests has also been proposed in the literature. The material constants of the constitutive law were interactively tuned until a good match between the cutting force obtained by FEM and the measured one is obtained. Kumar et al. [9] and Hua and Shivpuri [10] utilized this approach and the derived material constants are found to reproduce the experimental results within $10 \%$ and $5 \%$ respectively. However, apart from being time consuming, these methods use the cutting force as a parameter to identify material constants. Since there is a compound effect of strain rate and temperature, it was found that the cutting force was less sensitive to errors in the material constants (Shrot and Bäker [11]). An alternative method (inverse method) has been developed based on machining tests as a characterization test (Guo [3], Tounsi et al. [12], Ozel and Zeren [13] and Limido [14]). In this method, the measured cutting forces and chip thickness were used to calculate, analytically, the flow stresses, strains, strain rates and 
temperatures in the primary shear zones. Then, the material constants were obtained using a nonlinear regression solution. The main advantage of this approach is that extreme conditions are achieved directly with machining tests. Most previous works rely on a reduced number of experiments to identify the constitutive law parameters which obviously affects the optimization procedure. The originality of this work lies in the use of response surface methodology (RSM) as a technique to improve the existing inverse method. Machining tests were carried out on 6061-T6 alloy.

\section{Methodology to identify material constants of Johnson-Cook}

The common Johnson-Cook constitutive model (Johnson and Cook [1]), was used in this study to represent the material flow stress at combined effect of strains, strain rates and temperatures. The Johnson-Cook model is given as follows:

$$
\bar{\sigma}=\left[A+B(\bar{\varepsilon})^{n}\right]\left[1+C \ln \left(\frac{\dot{\bar{\varepsilon}}}{\dot{\bar{\varepsilon}}_{0}}\right)\right]\left[1-\left(\frac{T-T_{\text {room }}}{T_{\text {melt }}-T_{\text {room }}}\right)^{m}\right]
$$

where $\bar{\sigma}$ is the equivalent flow stress, $\bar{\varepsilon}$ is the plastic equivalent strain, $\dot{\bar{\varepsilon}}$ is the equivalent strain rate, $\dot{\bar{\varepsilon}}_{0}$ is the reference strain rate, $T$ is the temperature of the work material, $T_{\text {melt }}$ is the melting point of the work material and $T_{\text {room }}$ is the room temperature. The material constants are as follows: $A$ is the yield strength coefficient; $B$ the hardening modulus; $C$ the strain rate sensitivity coefficient; $n$ the hardening coefficient and $m$ the thermal softening coefficient. The material constants $(A, B, n, C, m)$ of equation (1) were determined using the inverse method. In this approach, the cutting forces and chip thickness are considered as input data while the output data are the equivalent flow stress, the plastic equivalent strain, the equivalent strain rate and the cutting temperature on the primary shear zone. The equivalent strain, strain rate, stress, and cutting temperature in the primary shear zone were calculated analytically using the Oxley model (Oxley [8]). A nonlinear regression solution based on the interior point algorithm was used to determine the material constants:

$$
\begin{aligned}
(A, B, n, C, m)= & \min \left(\sum _ { i = 1 } ^ { n } \left[\left(A+B(\bar{\varepsilon})^{n}\right)\left(1+C \ln \left(\frac{\dot{\bar{\varepsilon}}}{\dot{\dot{\varepsilon}_{0}}}\right)\right)(1\right.\right. \\
& \left.\left.\left.-\left(\frac{T-T_{\text {room }}}{T_{\text {melt }}-T_{\text {room }}}\right)^{m}\right)-\sigma_{\text {exp }}\right]^{2}\right)
\end{aligned}
$$

In the present work, the use of the RSM to cover a large number of cutting conditions during the optimization procedure is proposed. The orthogonal cutting experiments are conducted using central composite design (CCD). The CCD models provide acceptable accuracy in the resolution of non-linear responses (Montgomery [15]). For three factors, the CCD can be represented graphically in 
space by points on the three-dimensional cube (Fig. 1). Each axis of this cube corresponds to a factor and each point in this space represents an experiment. According to the CCD, a total of 16 experiments have been generated including $2^{n}\left(2^{3}=8\right)$ factor points, $2 \times n(2 \times 3=6)$ star points, and two center points (one replication). The independent variables used in this study consist of rake angle $(\alpha)$, cutting speed (V) and feed rate (f). The upper limit of a factor was coded as $+1.68(\sqrt[4]{8})$, and the lower limit as -1.68 ; these values were used to calculate the machining parameters. Table 1 shows the results of 16 experiments forming a central composite design and four extra conditions (\#17, \#18, \#19 and \#20) were performed for validation purpose. By using RSM and CCD, a second-order model Eqn. (3), has been developed with 95\% confidence level.

$$
y=\beta_{0}+\sum_{i=1}^{K} \beta_{i} x_{i}+\sum_{i=1}^{K} \beta_{i i} x_{i}^{2}+\sum_{i<j}^{K} \beta_{i j} x_{i} x_{j}+\epsilon
$$

where $y$ is the corresponding response and $x_{i} x_{j}$ are the values of the ith and $\mathrm{jth}$ machining process parameters. The terms $\beta_{0}, \beta_{i}, \beta_{i i}, \beta_{i j}$ are the regression coefficients and the residual $\epsilon$ represents the experimental error of the observations. So by using the machining parameters, such as rake angle $(\alpha)$, cutting speed (V) and feed rate (f), the relationship between the response surface $y$ and these machining parameters can be formulated as follows:

$$
\begin{gathered}
y=\beta_{0}+\beta_{1} V+\beta_{2} f+\beta_{3} \alpha+\beta_{4} V^{2}+\beta_{5} f^{2}+\beta_{6} \alpha^{2}+\beta_{7} V f \\
+\beta_{8} V \alpha+\beta_{9} f \alpha
\end{gathered}
$$

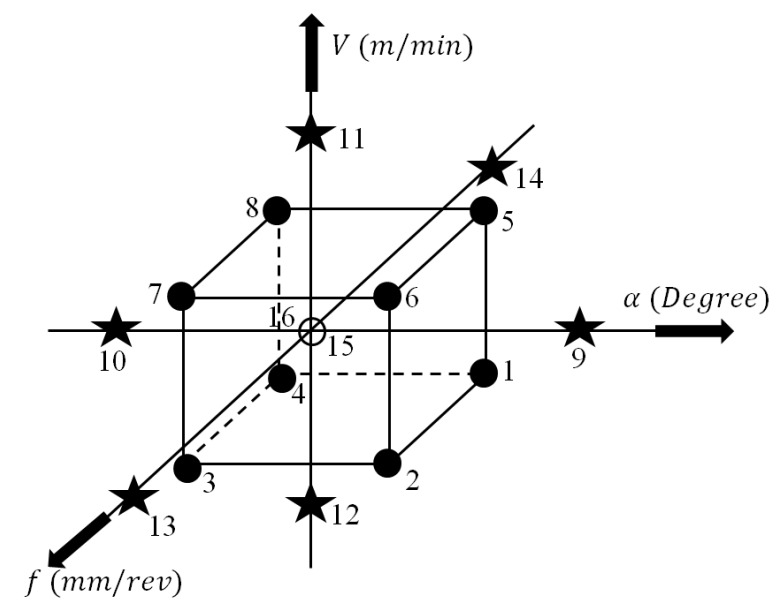

Figure 1: Central composite design of experiment for three factors. 
Table 1: Central composite design matrix for orthogonal cutting experiments.

\begin{tabular}{ccccccc}
\hline Test & \multicolumn{3}{c}{ Coded variables } & \multicolumn{3}{c}{ Actual variables } \\
\hline & $\begin{array}{c}\text { Speed } \\
V(\mathrm{~m} / \mathrm{min})\end{array}$ & $\begin{array}{c}\text { Feed } \\
f(\mathrm{~mm} / \mathrm{rev})\end{array}$ & $\begin{array}{c}\text { Rake angle } \\
\alpha(\text { deg. })\end{array}$ & $\begin{array}{c}\text { Speed } \\
V(\mathrm{~m} / \mathrm{min})\end{array}$ & $\begin{array}{c}\text { Feed } \\
f(\mathrm{~mm} / \mathrm{rev})\end{array}$ & $\begin{array}{c}\text { Rake angle } \\
\alpha(\text { deg. })\end{array}$ \\
\hline 1 & 1 & -1 & 1 & 1300 & 0.07 & 5 \\
2 & -1 & -1 & -1 & 600 & 0.07 & -5 \\
3 & 0 & 0 & -1.68 & 950 & 0.16 & -8 \\
4 & -1 & -1 & 1 & 600 & 0.07 & 5 \\
5 & 1.68 & 0 & 0 & 1539 & 0.16 & 0 \\
6 & 0 & -1.68 & 0 & 950 & 0.01 & 0 \\
7 & 1 & -1 & -1 & 1300 & 0.07 & -5 \\
8 & -1.68 & 0 & 0 & 361 & 0.16 & 0 \\
9 & -1 & 1 & -1 & 600 & 0.25 & -5 \\
10 & -1 & 1 & 1 & 600 & 0.25 & 5 \\
11 & 0 & 0 & 1.68 & 950 & 0.16 & 8 \\
12 & 0 & 0 & 0 & 950 & 0.16 & 0 \\
13 & 1 & 1 & 1 & 1300 & 0.25 & 5 \\
14 & 1 & 1 & -1 & 1300 & 0.25 & -5 \\
15 & 0 & 0 & 0 & 950 & 0.16 & 0 \\
16 & 0 & 1.68 & 0 & 950 & 0.31 & 0 \\
17 & 0.86 & 0 & 0 & 1250 & 0.16 & 0 \\
18 & 0 & 0.44 & 0 & 950 & 0.20 & 0 \\
19 & 0 & -0.66 & 0 & 950 & 0.10 & 0 \\
20 & -0.86 & 0 & 0 & 650 & 0.16 & 0 \\
\hline
\end{tabular}

\section{Experimental details}

Orthogonal machining tests using a sharp and uncoated carbide cutting inserts (K68 grade Kennametal Inc. with $11^{\circ}$ clearance angle) were carried out on MAZAK NEXUS 410A 3-axes CNC machine under dry cutting conditions (Fig. 2). The inserts were mounted on the left hand tool holder, CTFPL2525M16

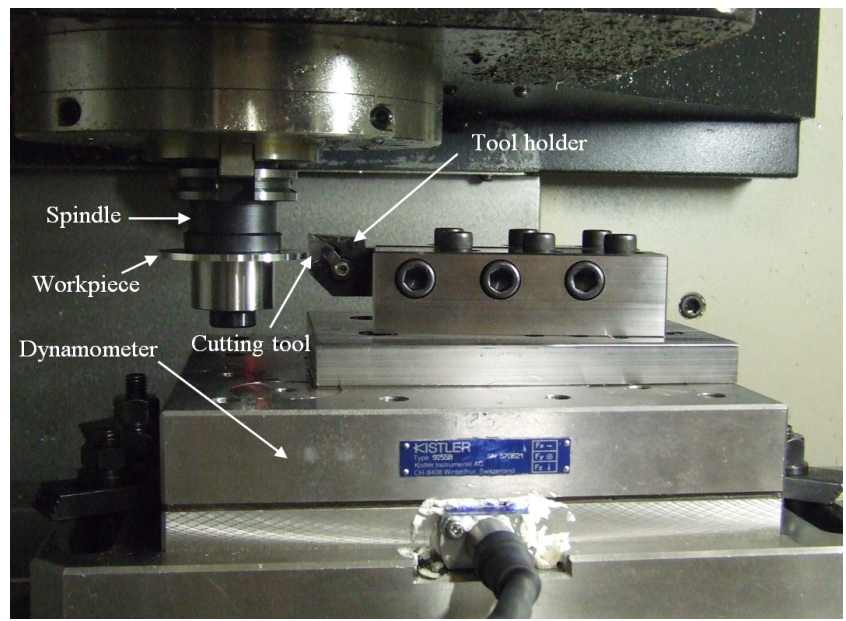

Figure 2: Experimental setup of the orthogonal cutting tests. 
with a back rake angle of $+5^{\circ}$. A new insert is used after each cutting experiments in order to eliminate the effect of eventual tool wear and to avoid important changes in the cutting edge radii. Discs of $75 \mathrm{~mm}$ in external diameter, $16 \mathrm{~mm}$ in internal diameter and $3.14 \mathrm{~mm}$ in thickness were selected as workpieces for these experiments. All orthogonal tests were conducted on Al6061-T6 alloy which is commonly used in aircraft applications. The cutting forces (tangential force, Fc, and thrust force, Ft) were measured using a Quartz three-component dynamometer (type 9255B) with the help of a Kistler charge amplifier. The thickness of the chips was then measured by a digital micrometer.

\section{Experimental results}

\subsection{Second-order models}

In this section, second-order models for cutting forces and chip thickness were developed based on experimental results shown in Table 2. The second-order response surface equation has been written, based on the CCD (Table 1), to determine the cutting force $F_{c}$, the thrust force $F_{f}$ and the chip thickness $t_{c}$. This analytical equation can be given in terms of the machining independent parameters: rake angle $(\alpha)$, cutting speed $(V)$ and feed rate $(f)$. The final regression coefficients as determined by STATGRAPHICS software to build the mathematical models (Eqn. (4)) for Al6061-T6 alloy are given in Table 3. The value of coefficient of determination $R^{2}$ for all observed response values is found to be between $94.2 \%$ and $95.33 \%$. While the value of the adjusted coefficient of determination $R_{a d j}^{2}$, is found to be between $85.51 \%$ and $96.69 \%$.

Table 2: $\quad$ Results of orthogonal cutting experiments performed on Al6061-T6.

\begin{tabular}{cccc}
\hline Test & $\begin{array}{c}\mathbf{F}_{\mathbf{c}} \\
(\mathbf{N})\end{array}$ & $\begin{array}{c}\mathbf{F}_{\mathbf{f}} \\
(\mathbf{N})\end{array}$ & $\begin{array}{c}\mathbf{t}_{\mathbf{c}} \\
(\mathbf{m m})\end{array}$ \\
\hline $\mathbf{1}$ & 190.5 & 91.8 & 0.163 \\
$\mathbf{2}$ & 92.9 & 177.8 & 0.261 \\
$\mathbf{3}$ & 387.6 & 229 & 0.426 \\
$\mathbf{4}$ & 208.5 & 123.4 & 0.202 \\
$\mathbf{5}$ & 357.6 & 148.1 & 0.323 \\
$\mathbf{6}$ & 30.3 & 30.3 & 0.061 \\
$\mathbf{7}$ & 136.1 & 128.7 & 0.218 \\
$\mathbf{8}$ & 455.5 & 282.4 & 0.553 \\
$\mathbf{9}$ & 406.5 & 330.4 & 0.6 \\
$\mathbf{1 0}$ & 558.6 & 216.8 & 0.523 \\
$\mathbf{1 1}$ & 344 & 129.7 & 0.378 \\
$\mathbf{1 2}$ & 399.6 & 188.3 & 0.388 \\
$\mathbf{1 3}$ & 472.6 & 143 & 0.296 \\
$\mathbf{1 4}$ & 418.4 & 228.2 & 0.641 \\
$\mathbf{1 5}$ & 401.7 & 193.8 & 0.428 \\
$\mathbf{1 6}$ & 543.4 & 246.1 & 0.645 \\
$\mathbf{1 7}$ & 378.7 & 163.6 & 0.321 \\
$\mathbf{1 8}$ & 472.1 & 202.9 & 0.441 \\
$\mathbf{1 9}$ & 265.5 & 144 & 0.292 \\
$\mathbf{2 0}$ & 407.9 & 203.1 & 0.427 \\
\hline
\end{tabular}


Table 3: $\quad$ Model parameters for Al6061-T6.

\begin{tabular}{cccc}
\hline & \multicolumn{3}{c}{ Coefficient } \\
\cline { 2 - 4 } Source & $\mathrm{F}_{\mathrm{c}}$ & $\mathrm{F}_{\mathrm{f}}$ & $\mathrm{t}_{\mathrm{c}}$ \\
& $(\mathrm{N})$ & $(\mathrm{N})$ & \\
\hline & & & \\
Constant & 406.487 & 190.385 & 0.413252 \\
$\mathbf{V}$ & -15.6447 & -35.3166 & -0.0480362 \\
$\mathbf{f}$ & 153.693 & 55.7936 & 0.16155 \\
$\mathbf{\alpha}$ & 23.3651 & -34.2181 & -0.0467022 \\
$\mathbf{V} \times \mathbf{V}$ & -7.00543 & 9.52306 & 0.0024412 \\
$\mathbf{f} \times \mathbf{f}$ & -50.3703 & -18.0211 & -0.0281144 \\
$\boldsymbol{\alpha} \times \boldsymbol{\alpha}$ & -24.5134 & -3.40011 & -0.0120843 \\
$\mathbf{V} \times \mathbf{f}$ & -12.4112 & -11.9112 & -0.0130704 \\
$\mathbf{V} \times \boldsymbol{\alpha}$ & -19.9113 & 5.72625 & -0.0330729 \\
$\mathbf{f} \times \boldsymbol{\alpha}$ & 4.53125 & -13.4538 & -0.0383646 \\
$\mathbf{R}^{\mathbf{2}}$ & 95.33 & 98.67 & 94.2 \\
$\mathbf{R}_{\mathbf{a d j}}^{\mathbf{a}}$ & 88.34 & 96.69 & 85.51 \\
\hline
\end{tabular}

These results indicate that the second-order model gives a good prediction of the cutting forces and chip thickness. In order to validate the developed models, the four machining tests (\#17, \#18, \#19 and \#20, listed in Table 1) were utilized. Figure 3 shows that the predicted values are in a good agreement with the measured ones for the three studied above mentioned parameters $\left(F_{c}, F_{f}\right.$ and $\left.t_{c}\right)$. Based on the high coefficients of determination $\left(R^{2}\right.$ and $\left.R_{a d j}^{2}\right)$ obtained for these three parameters and the results shown in Fig. 3, the developed model can adequately be used to investigate a large number of cutting conditions within fixed ranges of cutting parameters such as feed, speed and rake angle. So, in the next section, the identification procedure will be performed with 99 cutting conditions.

\subsection{Verification of the proposed approach}

The developed second-order models (Section 4.1, Table 3), allow to define a set of cutting conditions at $0^{\circ}$ rake angle. So, the obtained results (cutting forces and chip thickness) will be used when calculating the physical quantities $\left(\bar{\varepsilon}_{A B}, \dot{\bar{\varepsilon}}_{A B}\right.$, $\left.\bar{\sigma}_{A B}, T_{A B}\right)$ in the primary shear zone. The nonlinear regression solution will then be used to determine the material constants.

Table 4 gives a clear comparison of the constants of Al6061-T6 material obtained by different methods including those obtained from the proposed approach. 


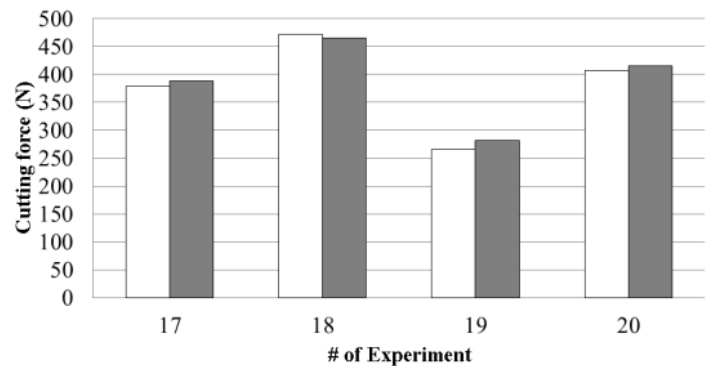

(a)

口EXP. (6061-T6)

aPRE. (6061-T6)

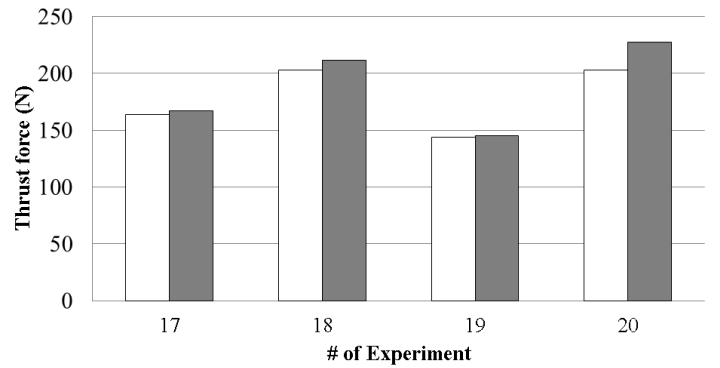

(b)

口EXP. (6061-T6)

$\square$ PRE. (6061-T6)

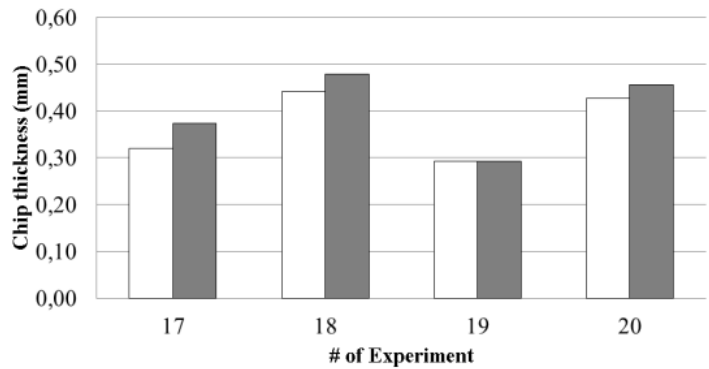

(c)

口EXP. (6061-T6)

aPRE. (6061-T6)

Figure 3: Comparison between the predicted and measured parameters: a) cutting force b) thrust force c) chip thickness.

Table 4: Al6061-T6 material constants obtained by different methods.

\begin{tabular}{|c|c|c|c|c|c|c|c|}
\hline Method & Set of JC & $\begin{array}{c}\boldsymbol{A} \\
(\boldsymbol{M P a})\end{array}$ & $\begin{array}{c}B \\
(M P a)\end{array}$ & $n$ & $C$ & $m$ & Ref. \\
\hline $\begin{array}{l}\text { Cutting and } \\
\text { compression }\end{array}$ & $\mathrm{JC} 1$ & 275 & 86 & 0.39 & $(*)$ & 1 & Guo [3] \\
\hline $\begin{array}{c}\text { exp. } \\
\text { SHBT }\end{array}$ & $\mathrm{JC} 2$ & 324 & 114 & 0.42 & 0.002 & 1.34 & $\begin{array}{c}\text { Lesuer et al. } \\
\text { [2] }\end{array}$ \\
\hline SHBT & $\mathrm{JC} 3$ & 335 & 85 & 0.11 & 0.012 & 1 & $\begin{array}{c}\text { Dabboussi and } \\
\text { Nemes [16] }\end{array}$ \\
\hline RSM & JC_RSM & 250 & 79.70 & 0.499 & 0.0249 & 1.499 & Daoud et al. \\
\hline
\end{tabular}

(*) C was determined as function of cutting speed and feed (Guo [3]).

Figure 4 shows the effect of the strain, strain rate and temperature on the flow stress using the coefficient of JC determined in the present study. As shown, the flow stresses increase with the stain and strain rate and decrease with the temperature. 

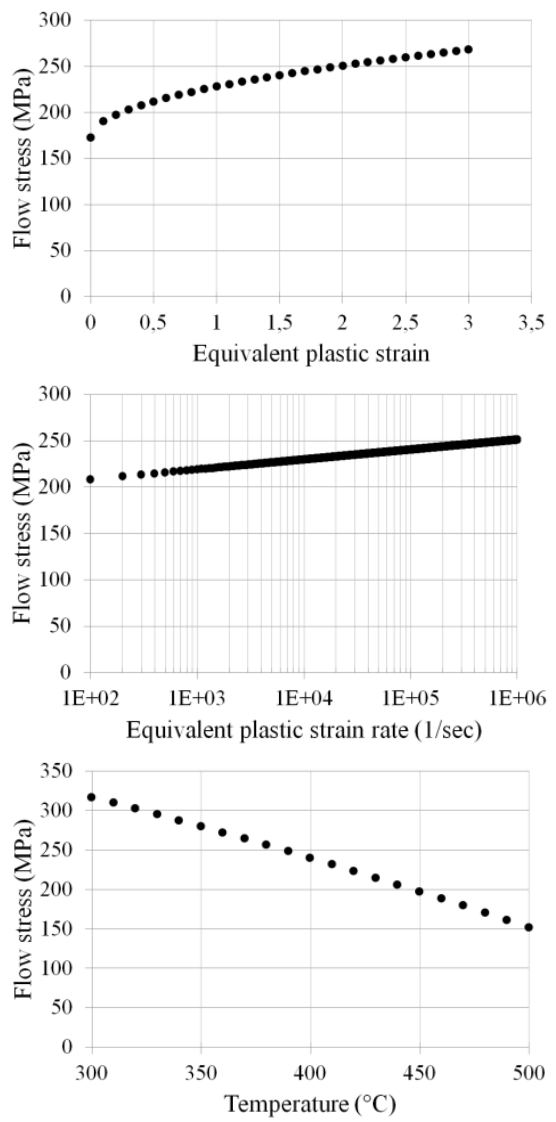

Figure 4: Influence of the strain, strain rate and the temperature on the material flow stress for 6061-T6.

With the determined material constants of 6061-T6, the efficiency and robustness of the RSM approach was verified using cutting tests. The relative average errors related to the predicted flow stress are summarized in Table 5.

Table 5: Relative errors of the predicted flow stress.

\begin{tabular}{cccc}
\hline Material & $\begin{array}{c}\text { Cutting } \\
\text { conditions }\end{array}$ & Material constants & Error (\%) \\
\hline & & JC1, Guo [3] & 17.50 \\
& Guo [3] & JC2, Lesuer et al. [2] & 17.94 \\
& & JC3, Dabboussi and Nemes [16] & 17.70 \\
Al6061-T6 & JC_RSM, Daoud et al. & 16.92 \\
\cline { 2 - 4 } & & JC1, Guo [3] & 22.26 \\
& \multirow{2}{*}{ RSM Table 7 } & JC2, Lesuer [2] & 20.16 \\
& & JC3, Dabboussi and Nemes [16] & 19.00 \\
& & JC_RSM, Daoud et al. & 18.37 \\
\hline
\end{tabular}


The validation of the material constants JC_RSM was ducted with the cutting conditions reported in Guo [3] and the ones listed in Table 6. The relative errors are $16.92 \%$ and 18.37 , respectively. These two values are close because their respective cutting conditions are in the same range. As shown in Table 5, the relative error obtained from the material set $\mathrm{JC} 1, \mathrm{JC} 2$ and $\mathrm{JC} 3$ is greater than when JC_RSM is used. This is because these material constants sets were obtained by tension-compression data or in combination with compression data and the flow stress is sensitive to the deformation mode (Johnson and Cook [1]).

Table 5 also shows that the material constants obtained by the proposed method (RSM) slightly overestimate the flow stress. This is considered acceptable considering the errors associated with the measurements of cutting forces, chip thickness and others. Although, using the RSM to determine the JC constants in this study improved the errors in flow stress, there are still some differences between the predicted and experimental results. This discrepancy comes from the weakness of constitutive material model i.e. Johnson-Cook to fully predict the complexity of material behaviour. Another consideration concerns the independent effect of strain, strain rate and temperature on the flow stress assumed in the Johnson Cook model which is not generally observed for most metals (Panov [5]). Finally, the analytical cutting models of Oxley [8], used in this work, are based on simplifications and some assumptions which may decrease the models' accuracies.

However, this comparison shows that the material constants obtained by the proposed method (RSM) gives smaller relative average error as compared to other methods with variation range of $16-18 \%$. The proposed methodology is therefore promising and could be used successfully for other materials.

Table 6: Cutting test data for Al6061-T6 ( $\alpha=0$ deg. ).

\begin{tabular}{|c|c|c|c|c|c|c|c|c|c|}
\hline $\begin{array}{l}\text { Te } \\
\text { st }\end{array}$ & $\left(\frac{\boldsymbol{m}}{\min }\right)$ & $\left(\frac{\boldsymbol{m} m}{r e v}\right)$ & $\begin{array}{c}\boldsymbol{F}_{\boldsymbol{c}} \\
(\boldsymbol{N})\end{array}$ & $\begin{array}{c}\boldsymbol{F}_{\boldsymbol{f}} \\
(\boldsymbol{N})\end{array}$ & $\begin{array}{c}\boldsymbol{t}_{\boldsymbol{c}} \\
(\boldsymbol{m m})\end{array}$ & $\bar{\varepsilon}_{A B}$ & $\begin{array}{l}\dot{\bar{\varepsilon}}_{A B} \\
\left(\times 10^{51}\right. \\
/ s)\end{array}$ & $\begin{array}{l}\boldsymbol{T}_{\boldsymbol{A B}} \\
\left({ }^{\circ} \boldsymbol{C}\right)\end{array}$ & $\begin{array}{c}\bar{\sigma}_{A B} \\
(\boldsymbol{M P a})\end{array}$ \\
\hline 1 & 363 & 0,07 & 188,1 & 182,6 & 0,289 & 1,26 & 2,05 & 172,8 & 260,1 \\
\hline 2 & 375 & 0,16 & 413,3 & 274,1 & 0,499 & 0,99 & 0,95 & 215,4 & 327,1 \\
\hline 3 & 387 & 0,25 & 536,8 & 328,8 & 0,651 & 0,86 & 0,64 & 199,4 & 303,9 \\
\hline 4 & 399 & 0,31 & 562,6 & 343,8 & 0,720 & 0,80 & 0,54 & 171,4 & 268,6 \\
\hline 5 & 939 & 0,07 & 202,5 & 117,3 & 0,225 & 1,02 & 5,41 & 249,9 & 372,4 \\
\hline 6 & 951 & 0,16 & 406,4 & 190,3 & 0,413 & 0,86 & 2,45 & 254,4 & 387,3 \\
\hline 7 & 963 & 0,25 & 508,8 & 226,4 & 0,544 & 0,76 & 1,63 & 211,9 & 339,6 \\
\hline 8 & 975 & 0,31 & 520,1 & 229,4 & 0,599 & 0,71 & 1,36 & 178,2 & 292,2 \\
\hline 9 & 1503 & 0,31 & 447,8 & 169,9 & 0,500 & 0,64 & 2,20 & 161,2 & 273,6 \\
\hline 10 & 1515 & 0,07 & 178,9 & 103,6 & 0,174 & 0,83 & 8,98 & 236,0 & 375,9 \\
\hline 11 & 1527 & 0,16 & 361,7 & 158,0 & 0,341 & 0,75 & 4,06 & 232,9 & 382,3 \\
\hline 12 & 1539 & 0.25 & 442,8 & 175,6 & 0,451 & 0,68 & 2,71 & 191,9 & 324,0 \\
\hline
\end{tabular}

\section{Conclusions and future work}

In the present work, an inverse method, based on orthogonal machining tests, was developed to determine the parameters of the JC constitutive law. These 
parameters are determined by fitting the data from cutting tests. Orthogonal machining tests were performed on Al6061-T6 material using a disc shape workpiece. In view of the high coefficients of determination obtained, that the second-order response surface equations used in this study, coupled to the central composite design, can adequately predict the cutting force $F_{c}$, the thrust force $F_{f}$ and the chip thickness $t_{c}$. For the studied alloy, results show that a small relative error of flow stress is obtained using material constants JC RSM. It is planned to bring this work a step further by validating the obtained material constants with a numerical simulation using finite element modeling. In this future study, the analytical and numerical predicted cutting forces and chip morphology will be compared to experimentally measured counterparts.

\section{References}

[1] Johnson, G.R., Cook, W.H., A constitutive model and data for metals subjected to large strains, high strain rates and high temperatures, Proceedings of the 7th International Symposium on Ballistics, 21, pp. 5417, 1983

[2] Lesuer, D.R., Kay, G. J., LeBlanc, M. M., Modeling Large-Strain, HighRate Deformation in Metals, Third Biennial Tri-Laboratory Engineering Conference Modeling and Simulation, Pleasanton, CA, November 3-5, 1999, pp., 2001.

[3] Guo, Y., An integral method to determine the mechanical behavior of materials in metal cutting, Journal of Materials Processing Technology, 142, pp. 72-81, 2003.

[4] Rule, W.K., A numerical scheme for extracting strength model coefficients from Taylor test data, International journal of impact engineering, 19, pp. 797-810, 1997.

[5] Panov, V., Modelling of behaviour of metals at high strain rates: Cranfield University, 2006.

[6] Sartkulvanich, P., Altan, T., Soehner, J., Flow stress data for finite element simulation in metal cutting: A progress report on madams, Machining science and technology, 9, pp. 271-88, 2005.

[7] Shatla, M., Kerk, C., Altan, T., Process modeling in machining. Part I: determination of flow stress data, International Journal of Machine Tools and Manufacture, 41, pp. 1511-34, 2001.

[8] Oxley, P.L.B., The mechanics of machining: an analytical approach to assessing machinability, 1989.

[9] Kumar, S., Fallböhmer, P., Altan, T., Computer Simulation of Orthogonal Metal Cutting Process: Determination of Material Properties and Effects of Tool Geometry on Chip Flow, Transactions - North American Manufacturing Research Institution of SME, pp. 33-8, 1997.

[10] Hua, J., Shivpuri, R., Prediction of chip morphology and segmentation during the machining of titanium alloys, Journal of Materials Processing Technology, 150, pp. 124-33, 2004. 
[11] Shrot, A., Bäker, M., Determination of Johnson-Cook parameters from machining simulations, Computational Materials Science, 52, pp. 298-304, 2012.

[12] Tounsi, N., Vincenti, J., Otho, A., Elbestawi, M., From the basic mechanics of orthogonal metal cutting toward the identification of the constitutive equation, International Journal of Machine Tools and Manufacture, 42, pp. 1373-83, 2002.

[13] Ozel, T., Zeren, E., A methodology to determine work material flow stress and tool-chip interfacial friction properties by using analysis of machining, Transactions - American Society of Mechanical Engineers Journal of Manufacturing Science and Engineering, 128, pp. 119, 2006.

[14] Limido, J., Étude de l'effet de l'usinage grande vitesse sur la tenue en fatigue de pièces aéronautiques: Université de Toulouse, Université Toulouse III-Paul Sabatier, 2008.

[15] Montgomery, D.C., Design and analysis of experiments: Wiley.com, 2006.

[16] Dabboussi, W., Nemes, J., Modeling of ductile fracture using the dynamic punch test, International journal of mechanical sciences, 47, pp. 1282-99, 2005 . 